Bullefin

of the Amenican

Mejeorological

socilotly

Volume $70 \quad$ Number $7 \quad$ July 1989

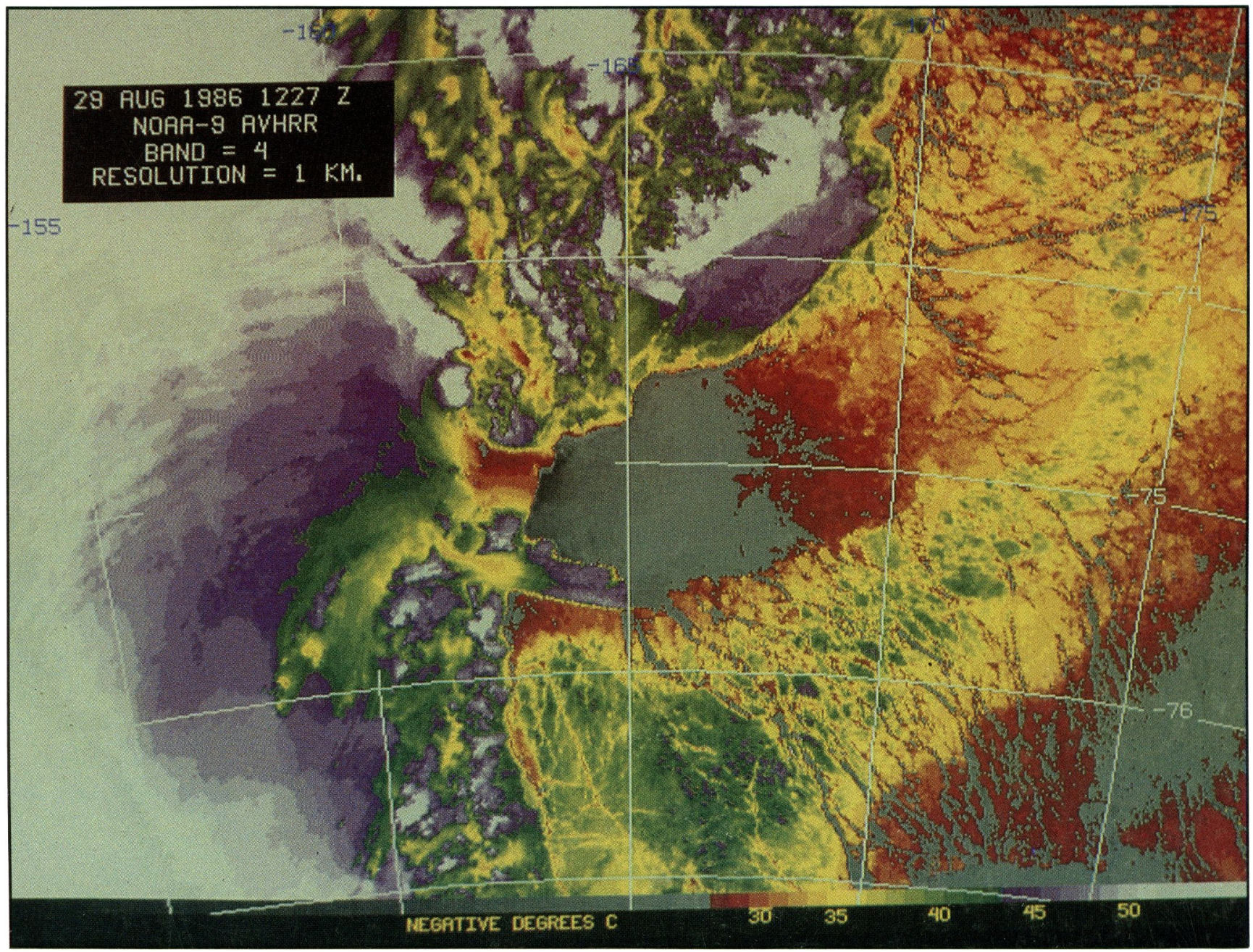




\section{Four Radars}

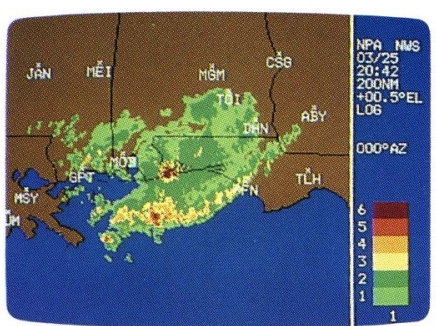

Pensacola, FL

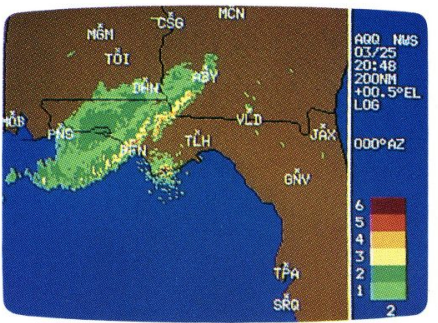

Apalachicola, FL

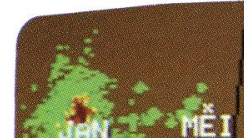

\section{西} (1)

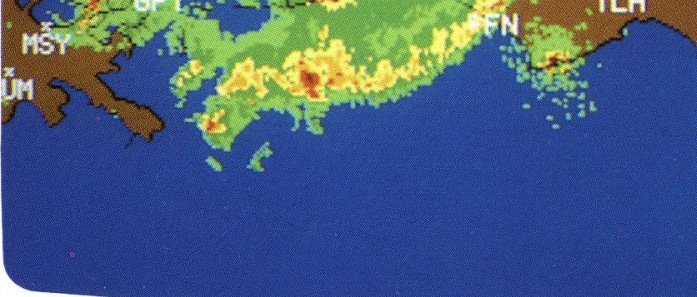

Individual radar displays can only show you part of the picture.

This composited image, centered in Pensacola, FL, combines echoes from four different radar sites and shows the true magnitude of the storm.

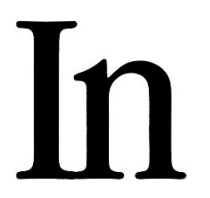

When the real weather story is outside the range of conventional radar, you need Alden's new radar compositing feature.

Compositing combines the echoes from multiple radar sites and displays them on a single screen. You can specify the radar sites you want, or automatically gather echoes from all the sites in your region-up to 16 in some areas!

The result is a display that's dramatically different from conventional radar. Instead of simply showing the weather that's here, com-

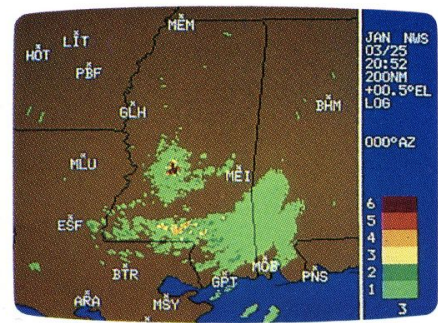

Jackson, MS
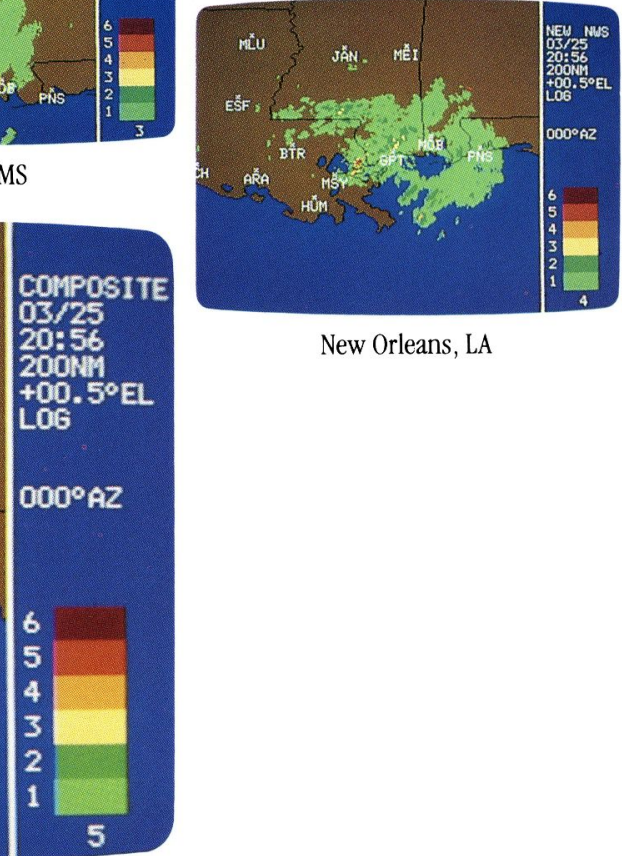

New Orleans, LA

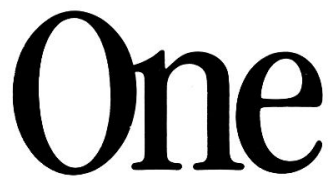

positing adds the weather that's on its way. In addition to compositing, Alden's Weather Radar System offers a full range of standard features, including zoom, time-lapse looping, customized backgrounds, and autodialer. Yet the cost is thousands less than other systems.

For more information on Alden's Weather Radar System, contact Alden Electronics, 46 Washington Street, Westborough, MA 01581 (508) 366-8851.

\section{ALDENELECTRONICS}




\section{TETHERED SYSTEMS}
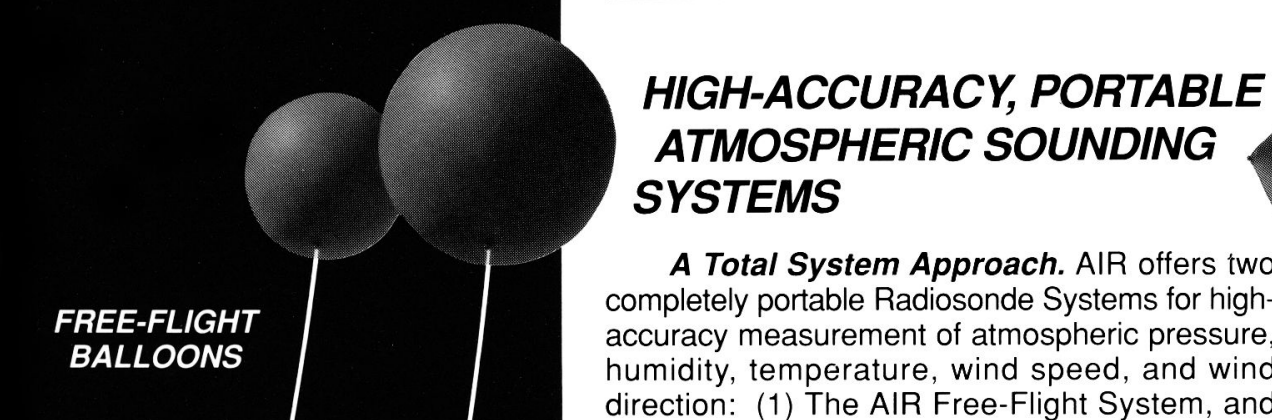

A Total System Approach. AIR offers two completely portable Radiosonde Systems for highaccuracy measurement of atmospheric pressure, humidity, temperature, wind speed, and wind direction: (1) The AIR Free-Flight System, and (2) The AIR Tethered System. Both systems are significantly lower in price and operating costs than alternative systems.

The ADAS Ground Station. An ADAS (Atmospheric Data Acquisition System) is the heart of each AIR sounding system. It receives and processes telemetered data from AIR's Airsondes ${ }^{\circledR}$ and Tethersondes $\left.{ }^{(}\right)$, calculates meteorological variables in real time, and produces digital output in meteorological units for computers or printers. When linked to an AIR Encoding Optical Theodolite, ADAS calculates wind in real time.

Free-Flight Airsondes. Two types are available: the spinning Airsonde, with dry and wet bulb thermistors, and the ducted Airsonde, using a carbon hygristor for $\mathrm{RH}$. Pressure is measured by a dual-diaphragm capacitance-type sensor. PTU data are telemetered every 5 seconds.

Tethersondes. Rising $1-2 \mathrm{~km}$ on a tethered balloon, the Tethersonde System measures PTU and winds with high vertical resolution in the boundary layer.
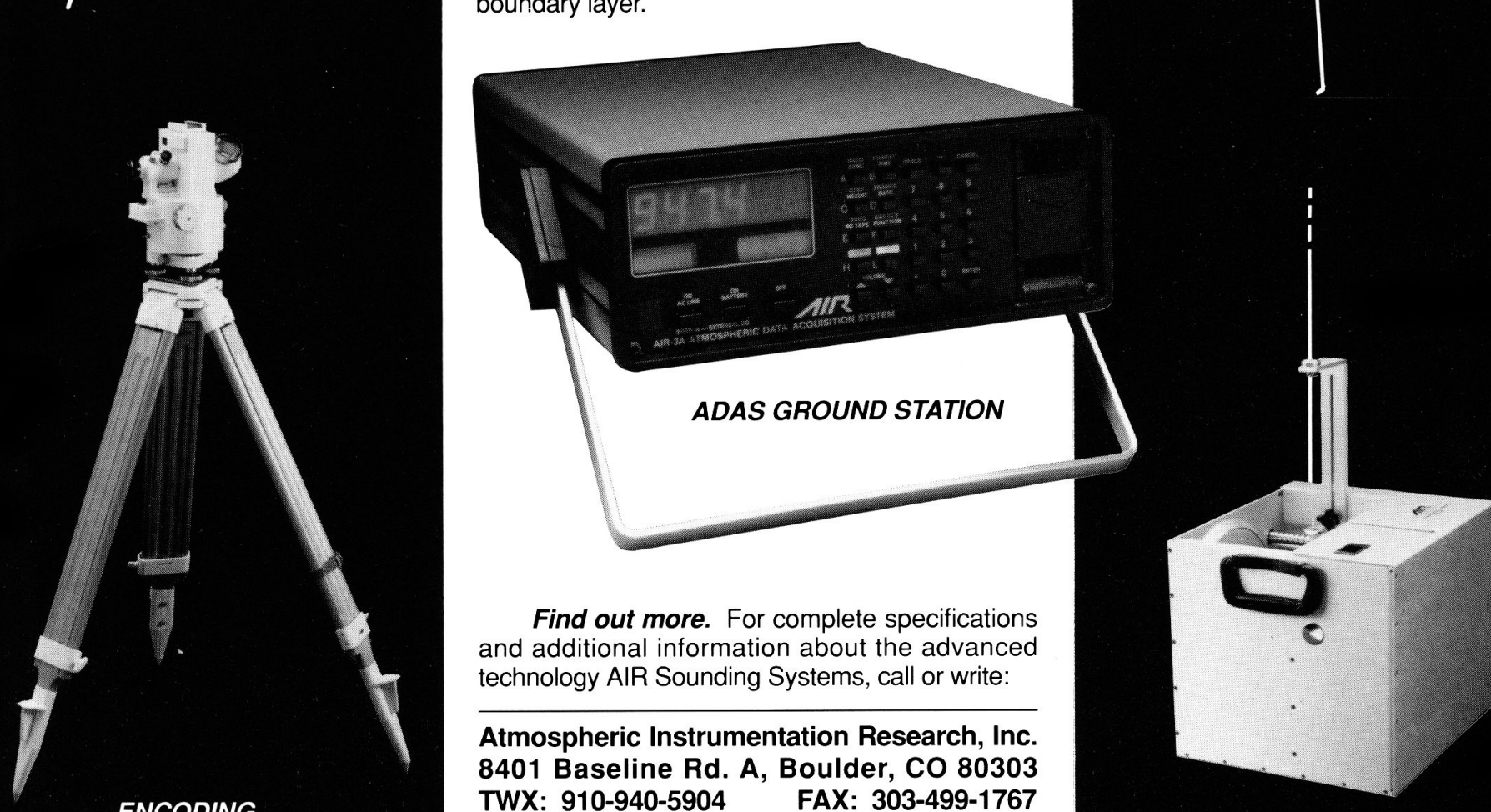

ENCODING OPTICAL THEODOLITE

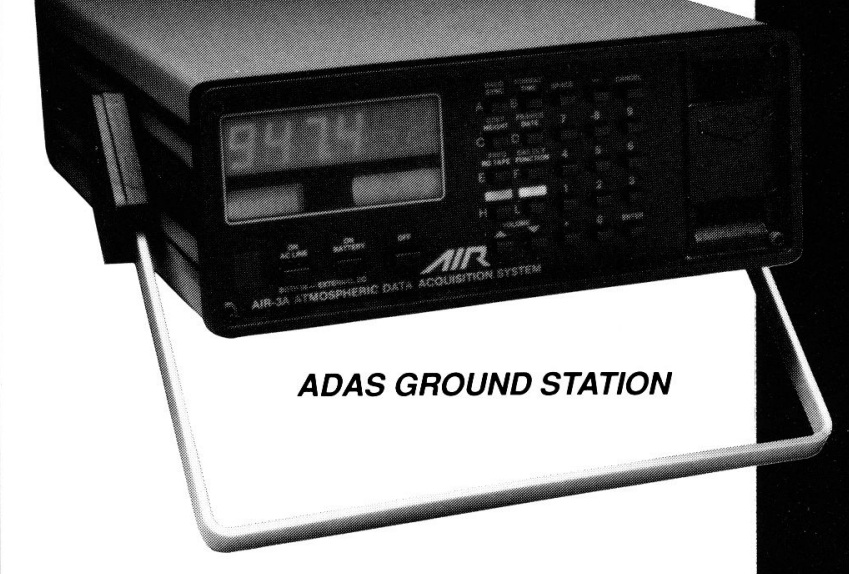

Find out more. For complete specifications and additional information about the advanced technology AIR Sounding Systems, call or write:

Atmospheric Instrumentation Research, Inc. 8401 Baseline Rd. A, Boulder, CO 80303 TWX: 910-940-5904 FAX: 303-499-1767 (303) 499-1701 Ext. 3

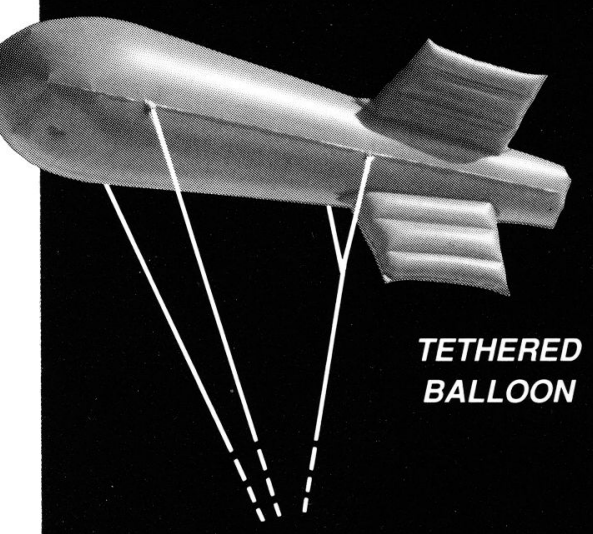

\section{TETHERSONDE}
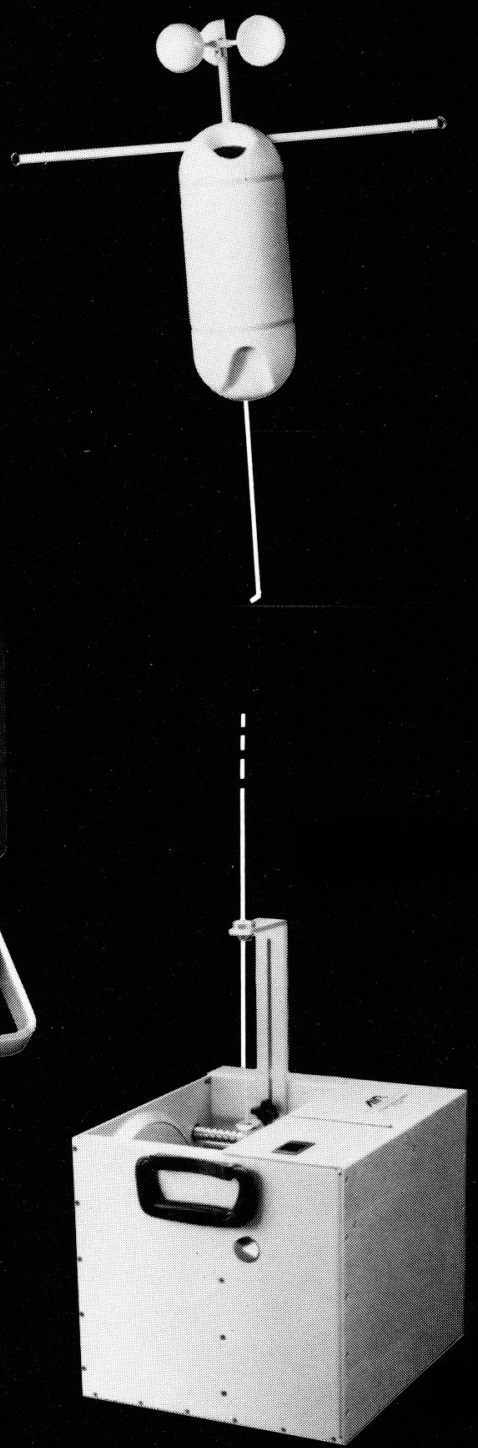

HEAVY DUTY WINCH 


\section{SUDDENLY,}

ALL OTHER

CEILOMETERS

FALL SHORT

COMPARED

TO THIS ONE.

\section{FEET

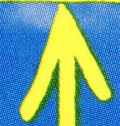

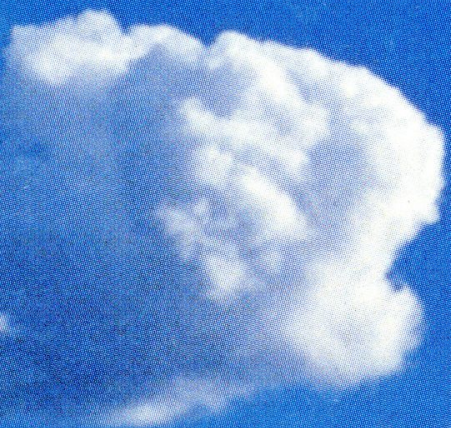
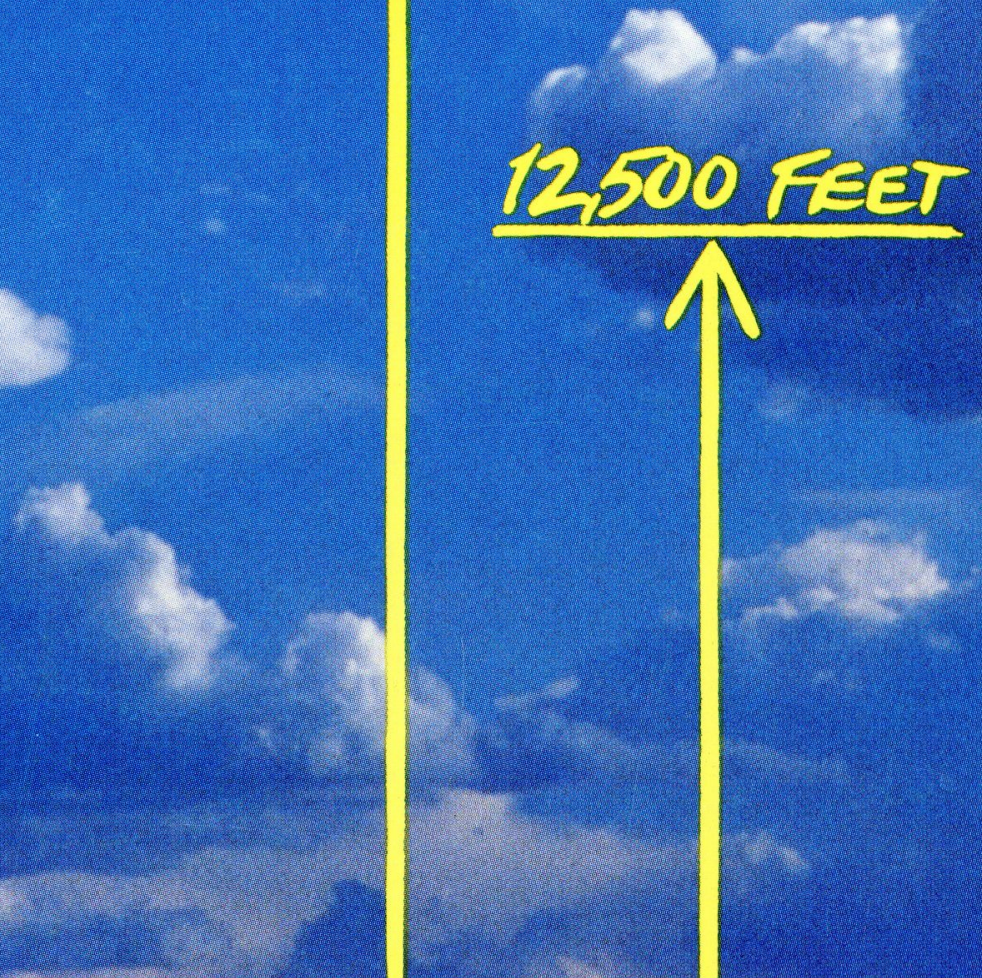

Imagine a ceilometer that measures twice as far as any other, and delivers ten times the resolution. Impossible? Not at all. Because that ceilometer is already here.

It's a dramatic breakthrough from Belfort: a vertical laser beam ceilometer that provides cloud based measurements to $25,000 \mathrm{ft}$. instead of the maximum $12,500 \mathrm{ft}$. of other such instruments.

What's more, it collects more information in much less time, with a resolution documented at ten times that of other laser beam ceilometers.

Already selected for use by the British Meteorological Office, the instrument is microprocessor controlled, self-

diagnostic and self-calibrating, eyesafe, features Klett Extinction profile, and provides remote monitoring and control plus PC compatible interface.

Learn why you no loriger have to limit your thinking about accurate cloud base measurements. Call or write for more information. Belfort Instrument,

727 S. Wolfe Street, Baltimore, MD 21231 301-342-2626 FAX: 301-342-7028 TELEX: 87528 BELFORT-BAL
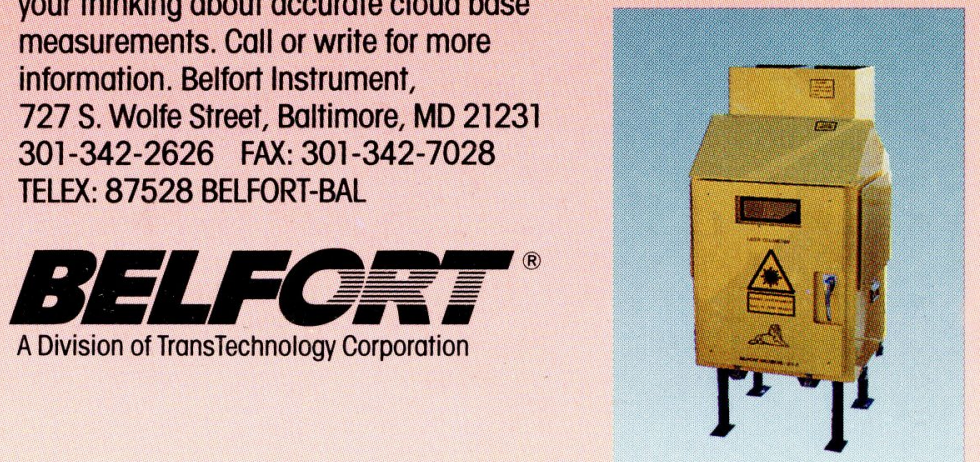
Bulletlin

of the Amer|lean

Meteonlog|leal

Socletty

Editor, Richard E. Hallgren

Technical Editor, Rick Lyons

Educational Affairs Editor,

David D. Houghton

Production Editor, Jean C. Thomas

News Editor, Brenda M. Gray

Meetings Editor, Evelyn Mazur

Editorial Assistant, Jackie G. Kramer

Advertising, Mary L. McMahon

The BULLETIN OF THE AMERICAN METEOROLOGICAL SOCIETY is the official organ of the Society, devoted to editorials, survey articles, professional and membership news, announcements, and Society activities. Editing and publishing are under the direction of Richard E. Hallgren. Executive Director. Members are encouraged to send information to be considered for publication. Send four copies of each manuscript (text and illustrations). For guidance on preparation and style, see "Information for Contributors" on inside covers of a recent AMS research journal.

AMS Officers, Councilors, and Commissioners: President, Joanne Simpson; President-Elect, James R. Mahoney; Executive Director, Richard E. Hallgren; Past Presidents, Roscoe R. Braham, Jr. and Albert J. Kaehn, Jr.; Councilors, William D. Bonner, Kirk Bryan, Jr., Robert A. Duce, Peter S. Eagleson, Russell L. Elsberry, Neil L. Frank, Elbert W. Friday, Jr. Robert A. Maddox, Thomas B. McKee, Ian D. Rutherford, James R. Scoggins, Robert J. Serafin, William L. Smith, Pamela L. Stephens, and Paul D. Try; Commissioners, David D. Houghton, Clifford J. Murino, Richard E. Orville, James L. Rasmussen, and Robert T. Ryan

The BULlETIN OF THE AMERICAN METEOROLOGICAL SOCIETY (ISSN 0003-0007) is published monthly by the American Meteorological Society at 45 Beacon St., Boston, MA 02108. Second-class postage paid at Boston, MA, and at additional mailing offices. Subscription price to members is included in annual dues ( $\$ 30$ per year). Subscription price to nonmembers is available on request: single issues are \$15 each. Address all business communications, purchase orders, and inquiries to the Executive Director, American Meteorological Society, 45 Beacon St. Boston, MA 02108 (617-227-2425). POSTMASTER: Send address changes to BULLETIN OF THE AMERICAN METEOROLOGICAL SOCIETY, 45 Beacon St., Boston, MA 02108.
Volume 70, No. 7, July 1989

articles

Satellite Analyses of Antarctic Katabatic Wind Behavior

........................................... H. Bromwich

Did Kepler's Supplement to Witelo Inspire Descartes' Theory of the Rainbow? ............................. D. Gedzelman

educational affairs

Professional Perspectives Seminar: Are You Prepared to be a Scientist? ...................................... B. Stull

Educational and Institutional Issues In Radar Meteorology

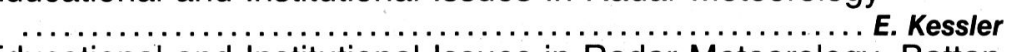

Educational and Institutional Issues in Radar Meteorology, Battan Memorial and 40th Anniversary Radar Meteorology Conference

D. Atlas, R. J. Serafin, and C. W. Ulbrich

768

\section{meeting reviews}

Review of the 18th Conference on Agriculture and Forest Meteorology ..................................... w. Gay 776

Speculations on the Future of Agricultural and Forest

Meteorology ........................... Rosenberg

\section{letters to the editor}

Cumulative Effects of Risk Associated with Environmental Hazards, Including Air Pollution.....R. A. Pielke and R. G. Derickson

A Response to "Cumulative Effects of Risks Associated with Environmental Hazards, Including Air Pollution"......... T. Downs

\section{programs}

11th Conference on Probability and Statistics, October 1-5,

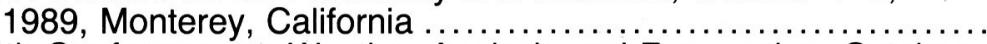

12th Conference on Weather Analysis and Forecasting, October 2-6, 1989, Monterey, California .............................

Third International Conference on Southern Hemisphere Meteorology and Oceanography, November 13-17, 1989, Buenos Aires, Argentina................................. announcements............... 790

book reviews ................ 793

new publications............... 804

news and notes.............. 806

25 years ago................ 805

50 years ago................ 814 about our members ............ 810

news from our chapters . . . . . . 812 necrologies. ................. 817 calendar of meetings........... 863 corporation members .......... 873
Cover: Thermal infrared image taken by the NOAA-9 polar orbiting meteorological satellite on 29 August 1986, showing the behavior of surface winds near Terra Nova Bay. This area is one of the windiest in the Antarctic. Colors represent ranges of emission temperatures and are coded from relatively warm (red) to relatively cold (purple). The computer processed image was designed to bring out temperature variations caused by strong winds blowing over ice surfaces during the polar night. The purple area on the left shows surface winds blowing down the elevated East Antarctic ice sheet toward the head of Reeves Glacier. The air accelerates and warms markedly as it descends several thousand feet down to sea level, producing the small red-orange area just to the left of center. The airstream then blows across Terra Nova Bay (gray area in center) and continues out into the ice-covered western Ross Sea (warm area to the right). For more information, see the article by D. H. Bromwich beginning on page 738 .

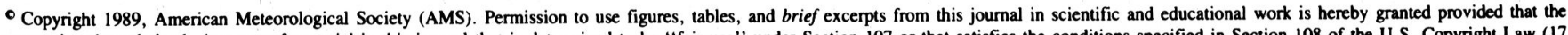

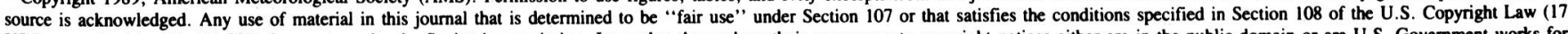

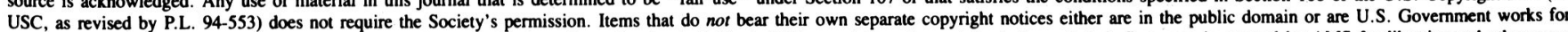

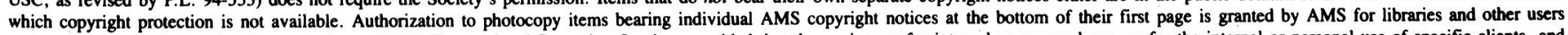

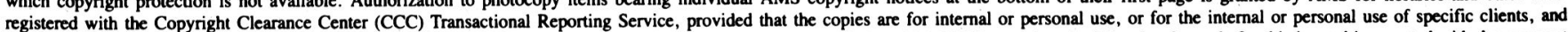

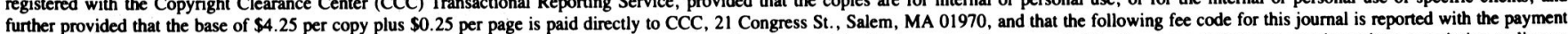

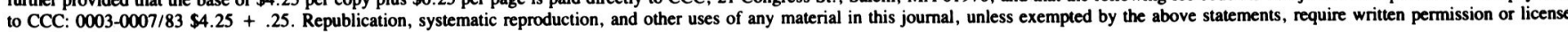
from the AMS. 